\title{
30
}

\section{Survival Rate Analyses of Watermains: A Comparison of Case Studies for Canada and Iran}

\author{
Ahmad Asnaashari, Edward A. McBean, Bahram Gharabaghi, Reza \\ Pourrajab and Isam Shahrour
}

Frequent watermain failure is a major challenge for water utilities around the world. A quantitative picture of failure time, and the rate of failure for different types of watermains, provide the opportunity for utilities to implement efficient proactive asset management strategies to minimize the overall cost of operations.

The Kaplan-Meier survival analysis is carried out for the time-to-failure in the watermains in two different case studies, one in Canada and one in Iran. At first, the times between failures for each material of watermains were estimated. Then, the rates of survival for the predominant pipe materials, namely cast and ductile iron, are compared. In both data sets, cast iron pipes show fast deterioration rates relative to other types of pipe materials.

The results demonstrate that cement mortar lined (CML) pipe and cathodic protection $(\mathrm{CP})$ are generally promising for improving the life expectancy of metal watermains

From the engineering point of view, the results provide asset management information for rehabilitation scenarios based on a list of priority parameters.

Asnaashari, A., E. McBean, B. Gharabaghi, R. Pourrajab and I. Shahrour. 2010. "Survival Rate Analyses of Watermains: A Comparison of Case Studies for Canada and Iran." Journal of Water Management Modeling R236-30. doi: 10.14796/JWMM.R236-30.

(C) CHI 2010 www.chijournal.org ISSN: 2292-6062 (Formerly in Dynamic Modeling of Urban Water Systems. ISBN: 978-0-9808853-3-0) 


\subsection{Introduction}

Asset management and rehabilitation are of great concern since they require large capital investments by municipalities. In 1997, the USEPA found that the United States needed to invest about $\$ 138$ billion to repair its water transportation infrastructure. They indicated that the single largest category of need was the replacement of existing water distribution pipes - about $\$ 77$ billion. Moreover, given the $\$ 72$ billion $(\mathrm{Cdn})$ tied up in water and wastewater infrastructure in Ontario alone, it is a significant problem that is intensifying with time. Here, survival analysis focuses on the lifetime of watermains, as input to rehabilitation and asset management planning.

Survival analysis is a branch of statistics that studies time-to-event data (Elisa and John, 2003). Death or failure is called an event in the survival analysis literature. This type of analysis attempts to answer questions such as: What is the survival probability of the patients under certain treatment? What is the fraction of patients who will survive past a certain time? How do particular factors benefit or affect the probability of survival? Survival analysis is called reliability analysis in engineering, and duration analysis in economics.

An intrinsic characteristic of survival data is the possibility for the censoring of observations; that is, the actual time until the event (e.g. pipe failure) is not observed. Such censoring may arise from withdrawal from the experiment or termination of the experiment. Because the response is usually a duration, some of the possible events may not yet have occurred when the period for data collection has terminated.

There is increasing literature concerning modeling and analysis of failure events, with a wide range of applications, including survival analysis of water pipelines, as of concern herein. Recently, Raed (2006) applied survival analysis to a model underlying the distribution of the failure time variable and assessment of the dependence of the failure time variable on the independent variables across a case study in France.

Such analyses have also been performed for several European and North American networks (e.g. Eisenbeis et al., 2000; Lei and Saegrov, 1998). In 1972, Cox introduced the proportional hazards model in order to estimate the effects of different covariates on the time to failure of a system. Kaara (1984) and Andreou (1986) introduced the application of a proportional hazards model for analyzing failures in water distribution networks. The scope of this chapter is directed towards survival modeling based on the Kaplan-Meier (1958) approach. 


\subsection{Data and Study Area}

The main challenge of any watermain failure analysis is obtaining reliable historical data on breakage rate in a water distribution system. This research examines and compares the watermain lifetimes installed by Canadian and Iranian water authorities. In the two countries which are the subject of this research, two municipalities, namely Etobicoke (Canada) and Marand (Iran), were chosen for the analyses. Table 30.1 lists watermains material and lengths for both study areas.

Table 30.1 Watermain length by material.

\begin{tabular}{lcc}
\hline \multirow{2}{*}{ Material } & \multicolumn{2}{c}{ Watermain Lengths (km) } \\
\cline { 2 - 3 } & Etobicoke (Canada) & Marand (Iran) \\
\hline Cast iron (CI) & 596.1 & 1530.5 \\
Ductile iron (DI) & 138.8 & 22.2 \\
Polyethylene (PE) & - & 214.8 \\
PVC & 33.3 & - \\
Galvanized iron (GI) & 0.2 & 8.5 \\
Others & 25.3 & - \\
Total & 793.8 & 397 \\
\hline
\end{tabular}

Marand serves approximately 35713 connections, corresponding to $397 \mathrm{~km}$ of watermains which vary from $25 \mathrm{~mm}$ to $400 \mathrm{~mm}$ diameter. As an indication of magnitude, Marand experiences $65-70$ breaks/100 km pipe/y for their $397 \mathrm{~km}$ of watermains (Abfa Azarbaijan, 2008).

Pipes in Etobicoke are predominantly cast iron (approximately 75\%), followed by ductile iron (approximately $17 \%$ ) and most (75\% to $85 \%$ ) are laid in silt or clay soils. The probability of a pipe breaking is significantly higher in silt and clay soils than in sand or gravel soils (McBean and Schuster, 2008). Analysis of the pipe records have shown that approximately $50 \%$ of the pipes in Etobicoke have broken at least once, with an average rate of breaking of 3.5 to 4 times, once a pipe has been broken.

Historic trends in watermain failures for Etobicoke dataset (Figure 30.1) demonstrate the effectiveness of cement-mortar lining (CML) and cathodic protection (CP) on pipe break reduction. Since CML and CP programs were initiated in 1983 and 2001 respectively (Figures 30.2 and 30.3), the number of failures started to decrease (see Figure 30.1). This confirms the result of McBean and Schuster (2008) which demonstrated CP is a cost-effective way to reduce breakage rate in the pipes. In the Greater Toronto area (GTA), CP ap- 
502 Survival Rate Analyses of Watermains: A Comparison of Case Studies ...

plied to DI pipes in silt or clay soils has increased the average time between breaks by almost $4 \mathrm{y}$.

Figure 30.2 shows that mostly cast iron (CI) watermains were coated as opposed to ductile iron (DI). This rate corresponds to break reduction in the CI in comparison to DI (Figure 30.1).

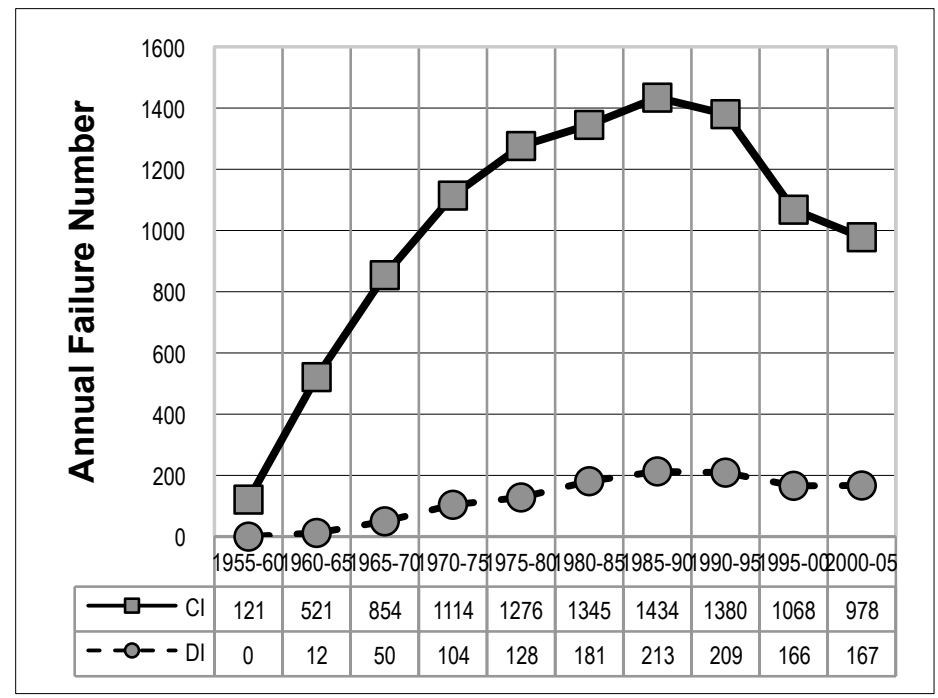

Figure 30.1 Historic trend of watermain failure in Etobicoke.

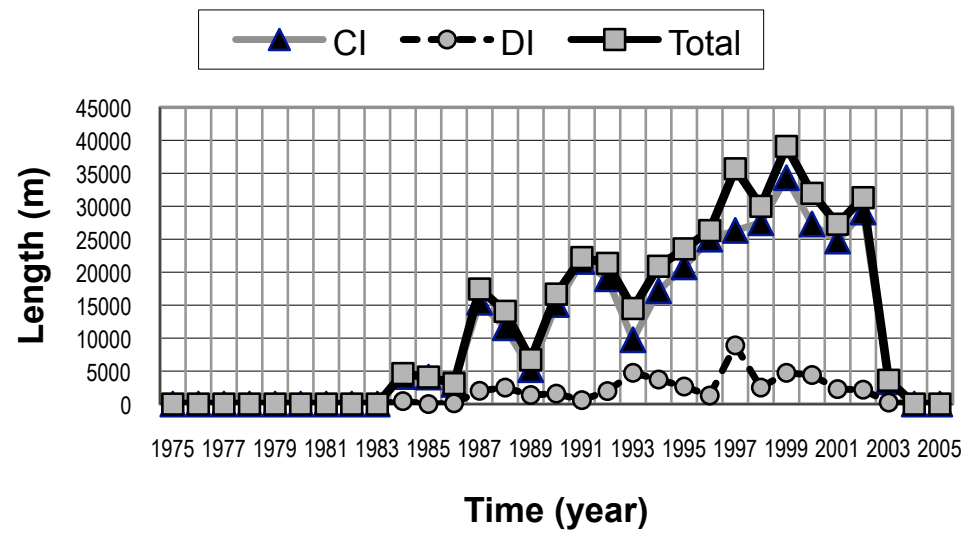

Figure 30.2 Length of watermains in Etobicoke subject to CML. 


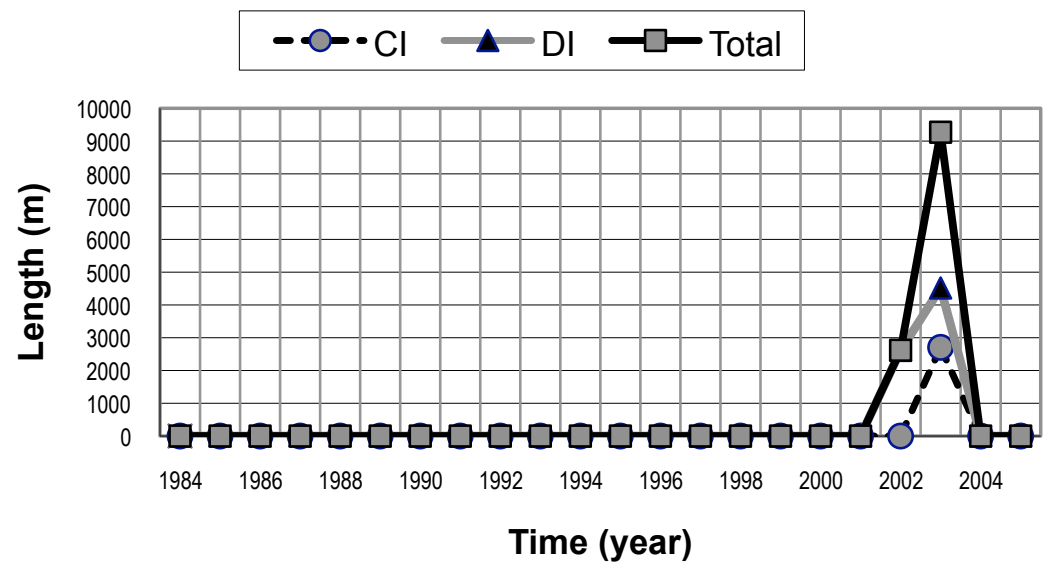

Figure 30.3 Length of watermains in Etobicoke subject to CP.

As shown in Figure 30.3, Etobicoke started a program of CP of its watermains in 2001. CP along with CML have aided in reducing watermains failure (Figure 30.1).

\subsection{Kaplan-Meier Model}

In this study, the Kaplan-Meier model is used to estimate the survival function for watermains.

According to available historic failure data, the start and end of the study's observation period was specified as being 1960-2008 for Etobicoke and 19952004 for Marand.

During the study period, some watermains had not failed and therefore the period of time until a failure occurs is unknown, and thus that observation time is censored. If the failure has occurred, the censoring value (CV) is set to 1 , otherwise $\mathrm{CV}=0$ (right-censored).

To establish the model, the failure dataset must be assembled into the proper format in the spreadsheet, namely the life table. As illustrated in Table 30.2, asset ID, number of failures, length of survival time, and the CV were entered in the columns. After a break, the newly introduced watermain has a new date of installation which is the date of the latest break now considered to be the date of installation. Table 30.2 provides the example of two watermains' survival dates. 
Table 30.2 Portion of life table for Etobicoke failure dataset.

\begin{tabular}{ccccc}
\hline \multirow{2}{*}{ Asset ID } & Number of & \multicolumn{2}{c}{ Length of survial time } & \multirow{2}{*}{ CV } \\
\cline { 3 - 4 } & Failures & Left time & Right time & \\
\hline $1495-001$ & 0 & $\mathbf{0 1 / 0 1 / 1 9 6 0}$ & $03 / 03 / 2004$ & 0 \\
$1495-001$ & 1 & $03 / 03 / 2004$ & $\mathbf{0 8} / \mathbf{0 1} / \mathbf{2 0 0 8}$ & 1 \\
$1823-019$ & 0 & $\mathbf{0 1 / 0 1 / 1 9 6 0}$ & $04 / 12 / 1984$ & 0 \\
$1823-019$ & 1 & $04 / 12 / 1984$ & $06 / 23 / 1987$ & 0 \\
$1823-019$ & 2 & $06 / 23 / 1987$ & $\mathbf{0 8} / \mathbf{0 1} / \mathbf{2 0 0 8}$ & 1 \\
\hline
\end{tabular}

According to Table 30.2, asset number 1495-001 experienced one failure on $03 / 03 / 2004$ during the study timeframe (01/01/1960-08/01/2008). Therefore, two rows were needed in the life table. The first row contains the entry time of the pipe into the study $(01 / 01 / 1960)$ and the time of failure for that pipe $(03 / 03 / 2004)$. In the CV column, the value 0 was considered for the binary code denoting that pipe failed. Since the pipe did not fail by the end of the study $(08 / 01 / 2008)$, and there is no information about its later survival, then the value 1 was assigned for $\mathrm{CV}$, which means this pipe is censored. However, each pipe in the study area is represented at least once. In other words, the total number of rows in the life table equals the number of watermains plus total number of failures in that case study. Hence, for asset 1823-019 with 2 failures, 3 rows are representing partial survival time.
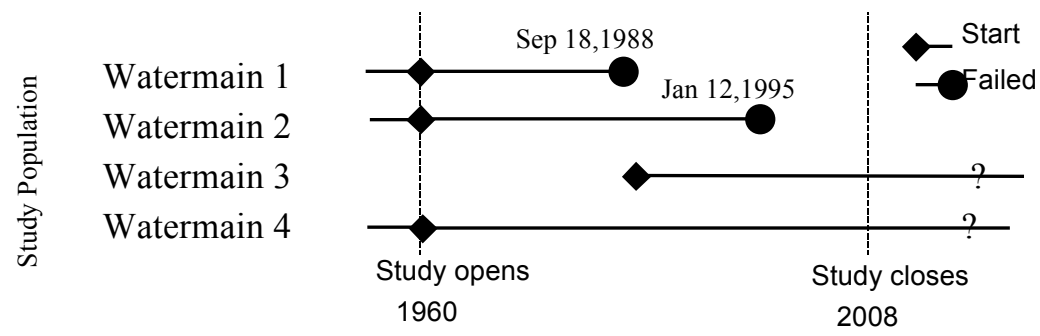

Figure 30.4 Study timeframe for Etobicoke watermain failure dataset.

Multiplying out the survival probabilities across the intervals (i.e. for each single observation) the survival function time is derived as:

$$
S(t)=\prod_{i=1}^{t}((n-i) /(n-i+1))^{\delta_{i}}
$$

where:

$$
\begin{aligned}
S(t) & =\text { estimated survival function, } \\
n & =\text { total number of cases in the life table, }
\end{aligned}
$$




$$
\begin{aligned}
t= & \text { time }(\mathrm{d}), \\
i= & \text { number of cases surviving up to time } t \\
\Pi= & \text { multiplication across all cases } \leq t, \text { and } \\
\delta_{i}= & 1 \text { if the } j \text { th case is uncensored (complete) } \\
& 0 \text { if it is censored. }
\end{aligned}
$$

The Kaplan-Meier survival plot, Figure 30.5, shows the rate of failure in three different watermain material types in Marand.

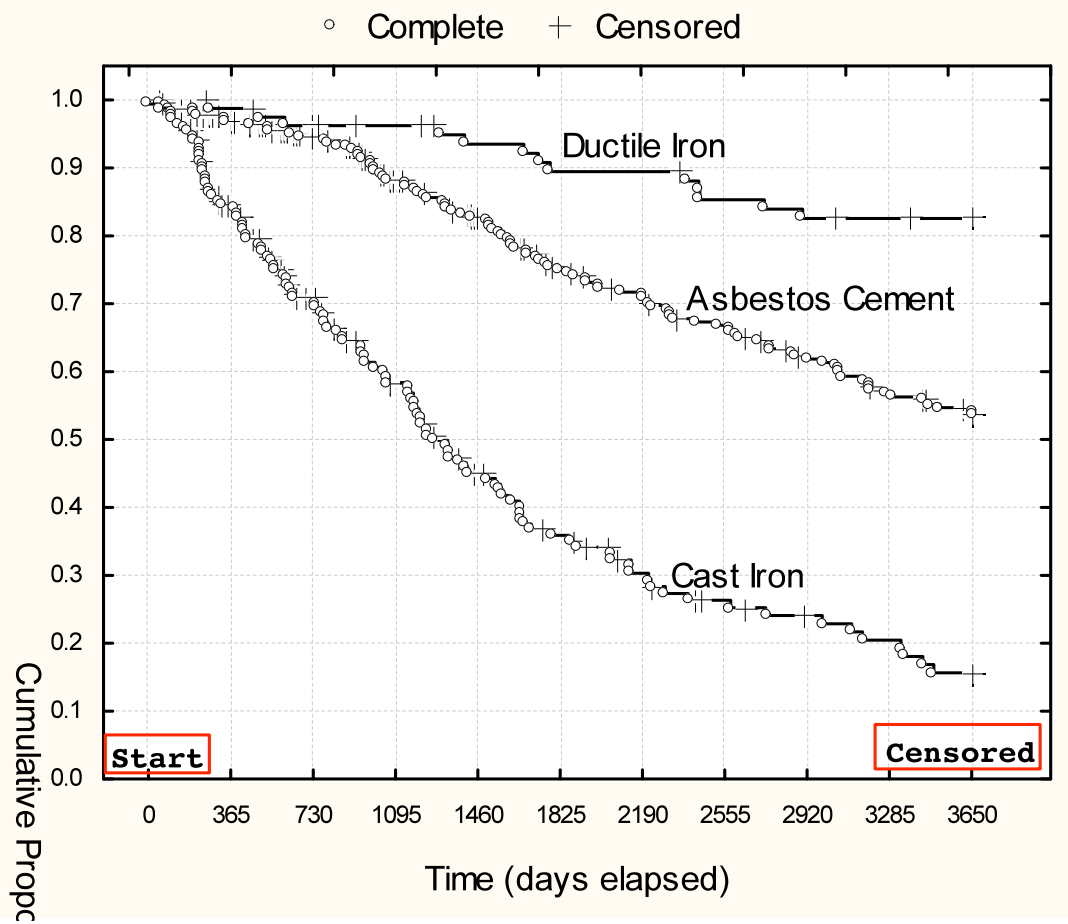

Figure 30.5 Survival rate of $\mathrm{DI}, \mathrm{Cl}$ and asbestos cement watermains in Marand.

The upper dashed lines, showing the influence of the time factor on the respective breakage rates, are nearly horizontal, indicating a modest deterioration rate in DI pipelines. It is clear that the ductile water pipelines in the Iranian study area have been deteriorating at a relatively steady rate. In contrast, the CI watermains have been deteriorating rapidly (lower curve). The survival function drops off more rapidly than the other curves within the $10 \mathrm{y}$ timespan covered by the study. Except for DI, asbestos cement watermains had fast sur- 
vival declines with time, as plotted in the middle of Figure 30.5.

In the failure dataset of Etobicoke municipality, watermains were evaluated during study timeframe (1960-2008). The survival probabilities of CI and DI were calculated by the Kaplan-Meier method and compared. Figure 30.6 displays visually that cumulative survival drops with every failure, whereas it remains unchanged with every censored observation (indicated by the plus signs). As a first glance, two survival curves in Figure 30.6 depict DI watermains are less likely to break, as compared to CI.

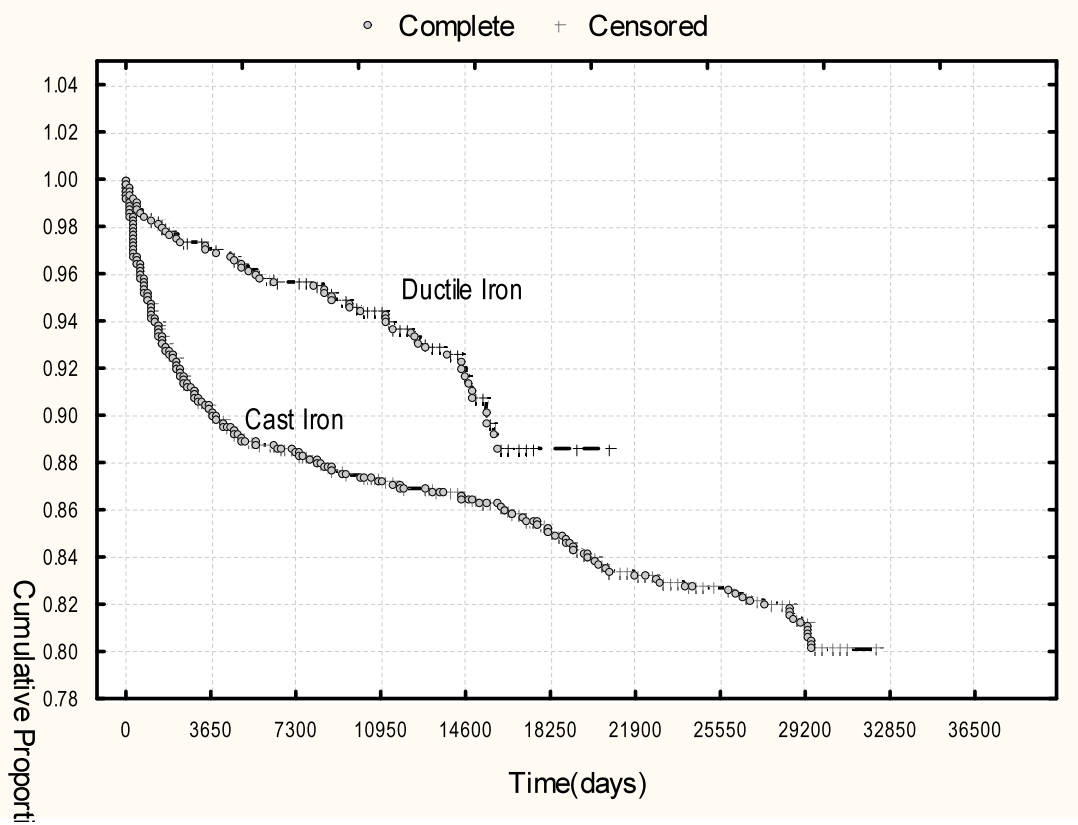

Figure 30.6 Survival curves for DI and $\mathrm{Cl}$ watermains in Etobicoke.

Figure 30.7 focuses on the DI and CI survival curve in Etobicoke. The plot fits three slopes on the CI survival curve. Survival rate has markedly decreased (slope A) by the end of the first 10 y ( $3650 \mathrm{~d}$ ). The rate of decrease becomes lower near the end of the fifth decade for CI (slope B). The last slope C refers to the the survival rate which is improved by the $\mathrm{CP}$ and $\mathrm{CML}$ programs at the end of the study period.

For the case studies presented here, comparison of DI and CI survival curves (Figures 30.5 and 30.6), shows that Etobicoke watermains have a greater probability to be in service in the network than Marand's watermains. 


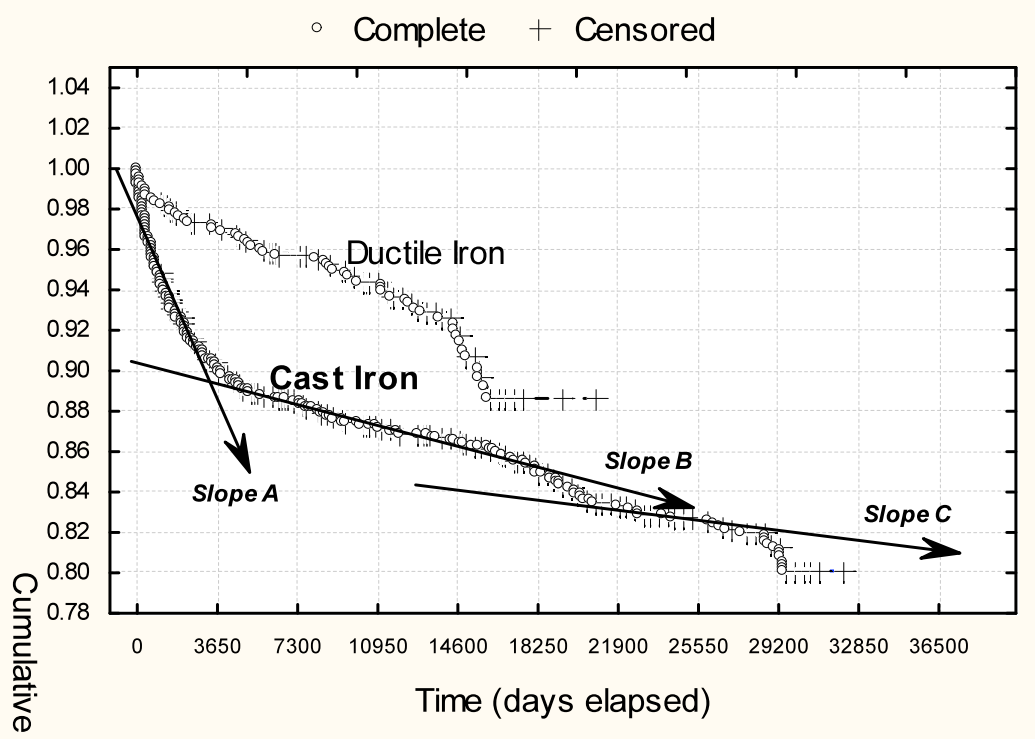

Figure 30.7 Survival curves for DI and Cl watermains in Etobicoke.

\subsection{Conclusion}

In this chapter, times between failures were analyzed for watermains in the cities of Etobicoke in Canada and Marand in Iran, using the non-parametric survival approach namely the Kaplan-Meier method.

Different Kaplan-Meier curves for material groups indicated that metallic and cement watermains have different rates of deterioration. The slopes of the Kaplan-Meier survival curve are important statistics, indicating whether failures are occurring rapidly or the failure rate is lower. The findings of this research show that the survival functions in the DI watermains have a slower drop-off in comparison with other pipe materials. Therefore, it can be concluded that the DI pipes have a greater chance of survival (time before failure). Also, as a result of Kaplan-Meier graph, CI watermains are seen to be more prone to breaking than other types of pipes for both study areas. Based on the results of Kaplan-Meier survival function, it is highly recommended to consider the Kaplan-Meier curves as an option for evaluation of the risk of failure in different pipe materials.

For the case studies presented here, comparisons of survival curves for both DI and CI watermains demonstrate CP and CML treatments reduce failure of 
metallic water distribution systems, thus extending the life-expectancy of those watermains. In the Iranian water network without CML and CP program, CI and DI pipelines have experienced greater failure rates.

\section{Acknowledgments}

The authors would like to thank the Etobicoke municipality in the GTA and the Water and Wastewater company of Azarbaijan-e-Sharghi for their contribuions in the data collection phase. This research was funded by the Canada Research Chairs program.

\section{References}

Abfa Azarbaijan, (2008). Annually failure reports on water distribution system. http://www.abfa-azarbaijan.com.

Andreou, S.A. 1986. Predictive models for pipe break failures and their implications on maintenance planning strategies for deteriorating water distribution systems. Ph.D. thesis. Department of Civil Engineering, Massachusetts Institute of Technology. Cambridge, Mass.

Asnaashari, A., McBean, Ed., Shahrour, I. , and Gharabaghi, B. (2009). Prediction of water pipeline failure frequencies using Multiple and Poisson regressions; IWA journal Water Science and Technology: Water Supply. Vol.9, No.1, pp. 9-19.

Cox, D. R. (1972). Regression Models and Life Tables. Journal of the Royal Statistical Society Series B 34 (2): 187-220.

Eisenbeis, P., Le Gauffre, P., and Saegrov S. (2000). Water infrastructure management: An Overview of European Models and Databases, AWWARF Infrastructure Conference and Exhibition Proceedings, Baltimore, Maryland, 2000.

Elisa, L.T., and John, W.W. (2003). Statistical Methods for Survival Data Analysis (3rd ed.), John Wiley and Sons, New York.

Kaara, A. F. (1984). A decision support model for the investment planning of the reconstruction and rehabilitation of mature water distribution systems. PhD thesis, MIT, Cambridge, MA.

Kaplan, E.L., and Meier, P. (1958). Nonparametric estimation from incomplete observations. J.of the American Statistical Association, 53, 1958, 457-481.

Lei, J., and Saegrov, S. (1998). Statistical approach for describing failures and lifetime of watermains. Water science and technology, 1998. 38(6): pp. 209-217.

McBean, E., and Schuster, C. (2008). Aging Water Infrastructure, An Emerging Crisis, Water Down Under, April, pp 2539-2545.

Raed J. (2006). Modélisation de la dégradation des réseaux d'eau en vue d'une gestion prévisionnelle. PhD Dissertation, University of Lille 1, France.

U.S. EPA. (1997). Drinking Water Infrastructure Needs Survey. First report to Congress. EPA/812/R-97/001. Office of Water, Washington, DC. 